\title{
UTILIZAÇÃO DE CHOCOLATES RICOS EM POLIFENÓIS E COM AÇÃO ANTIOXIDANTE: BUSCA EM BASES DE PATENTES
}

\author{
Marta Magalhães Guimarães, Tamiris Vilas Boas Figueiredo, Bruna Aparecida Souza Machado, \\ Janice Izabel Druzian
}

Faculdade de Farmácia, Departamento de Análises Bromatológicas, Universidade Federal da Bahia. Campus de Ondina, Salvador - BA - Brasil, CEP 40170-290 (brunamachado@ufba.br)

\section{RESUMO}

O interesse de pesquisadores e produtores em compostos fenólicos, ou polifenóis, deve-se à grande abundância na dieta humana, ao reconhecimento das propriedades antioxidantes dessas substâncias, e ao provável papel na prevenção de várias doenças associadas com o estresse oxidativo. Assim, tem sido crescente o direcionamento de pesquisas voltadas para a descoberta de produtos naturais com atividade antioxidante, como os polifenóis, de modo que estes atuem como alimentos funcionais. O presente estudo visa fornecer informações de pesquisas desenvolvidas sobre a avaliação dos teores de polifenóis e atividade antioxidante em chocolates, constituídos por diferentes concentrações de liquor de cacau. Ainda existem poucas patentes relacionadas ao uso do chocolate como uma fonte de fenólicos antioxidantes para a população. É importante, então, esclarecer qual a concentração efetiva e quais concentrações possibilitam os efeitos esperados através do consumo alimentar, informações que ainda não constam nas produções científicas obtidas no estudo.

Palavras Chave: polifenóis, antioxidantes, alimentos funcionais, chocolate.

\section{ABSTRACT}

The interest of researchers and producers in phenolic compounds, or polyphenols, due to the abundance in the human diet, the recognition of the antioxidant properties of these substances, and the probable role in prevention of various diseases associated with oxidative stress. Thus it has been increasing the targeting of research for the discovery of natural products with antioxidant activity, such as polyphenols, so that they act as functional foods. This study aims to provide research information developed on the evaluation of the polyphenols and antioxidant activity in chocolate, made up of different concentrations of cocoa liquor. Although there are few patents related to the use of chocolate as a source of phenolic antioxidants to the population. It is important then to clarify the effective concentration and concentrations which allow the effects expected from the food consumption information that is not in the scientific production obtained in the study.

Key words: polyphenols, antioxidants, functional foods, chocolate. 


\section{INTRODUÇÃO}

O cacaueiro pertence à ordem Malvales, família Malvaceae, gênero Theobroma, espécie Theobrom cacao L., único utilizado comercialmente para a produção de chocolate. Os astecas e outros grupos de língua nahuatl denominavam o cacaueiro de "cacaohoaquahuitl”, os frutos de "cachocentli" e suas sementes de "cacaoatl”, nome utilizado atualmente para a espécie. Em 1737, Lineu denomina o gênero de Theobroma, que significa alimento dos deuses, em referência à origem divina atribuída ao cacaueiro pelos povos mesoamericanos (LOPES et al, 2011; EFRAIM, 2009).

O cacau é normalmente cultivado nos trópicos, por pequenos agricultores de países do terceiro mundo. Seu cultivo estende-se da Colômbia, Venezuela, América Central e México. Ao dispersarse ao longo do rio Amazonas, alcança também as Guianas. Saindo das Américas cerca de $70 \%$ da produção mundial é proveniente da África Ocidental, principalmente da Costa do Marfim (40\%), Gana (20\%), Nigéria (5\%) e Camarões (5\%). O Brasil até 1989 era o segundo maior produtor de cacau do mundo caindo para a sexta posição, responsável por $4 \%$ do total mundial depois do aparecimento desta doença. A Bahia ainda é o maior produtor de cacau no Brasil, com 64\% do total produzido, seguido por Pará (25\%), Rondônia (8\%) e Espírito Santo (3\%) (LOPES et al., 2011).

De acordo com o ICCO (International Cocoa Organization), os maiores produtores mundiais de cacau são a Costa do Marfim com 1.242 mil toneladas na safra 2009/10, seguida por Gana (632 mil toneladas), Indonésia (550 mil toneladas), Nigéria (240 mil toneladas), Camarões (205 mil toneladas), Brasil (161 mil toneladas), Equador (160 mil toneladas) e Papua Nova Guiné (50 mil toneladas) (ICCO, 2011). Ao lado da indiscutível importância econômica, o cacau tem um grande valor ecológico. Cultivado racionalmente, em condições que se assemelham às do seu "habitat" natural, em florestas, com um sombreamento permanente de árvores de maior porte, o cacaueiro protege o solo dos efeitos da erosão e da lixiviação (carreamento de elementos nutritivos pelas águas). Suas plantações substituem a floresta original sem destruir o ambiente ecológico existente, preservando a heterogeneidade e com ela o micro-clima e a vida das espécies vegetais e animais das áreas cultivadas (EFRAIM, 2004).

A produção de cacau vem crescendo e vários estudos são direcionados a produção e caracterização do chocolate. Uma das etapas do processamento para a produção de amêndoas de cacau é a fermentação, resultando no subproduto "mel" de cacau, matéria-prima ainda não aproveitada pela indústria beneficiadora de alimentos, sendo sua comercialização realizada na forma in natura. Atualmente, os pequenos produtores extraem o "mel de cacau” por prensagem e desenvolvem produtos de forma artesanal a exemplo da geléia de cacau e vinagre.

A polpa do cacau é constituída por um conjunto de células esponjosas mucilaginosas contendo água, frutose, glicose, sacarose, ácido cítrico e vários sais inorgânicos. A testa secreta a mucilagem e atua como via de transporte entre os cotilédones e a polpa mucilaginosa. O cotilédone apresenta células contendo reservas proteicas, lipídeos, amido e células polifenólicas. No tecido fresco predominam células contendo numerosos e regulares glóbulos lipídicos que revestem ordenadamente a face interna da membrana celular. As células polifenólicas apresentam um grande e único vacúolo preenchido por polifenóis sendo responsáveis pela cor dos cotilédones (MARTINI, 2004).

O “mel” de cacau é um líquido amarelo pálido, resultante da quebra da mucilagem (polpa) em torno da semente de cacau, constituído de água, açúcar (10-18\%), ácido não volátil (ácido cítrico - 0,771,50\%) e pectina (5,0-6,9\%), além de outros componentes (Tabela 1). Esses constituintes favorecem

Cadernos de Prospecção - ISSN 1983-1358 (print) 2317-0026 (online), 2012. vol.5, n.3, p.168-177

D.O.I.: 10.9771/S.CPROSP.2012.005.018 
a produção de produtos fermentados como bebidas alcoólicas e alguns alimentos concentrados devido ao elevado teor de açúcares que beneficia a espontaneidade dos processos fermentativos quando armazenados a temperatura ambiente (OTTERER, 1999).

Diante do exposto, o objetivo deste trabalho foi realizar um estudo de prospecção com a finalidade e avaliar o panorama mundial de pesquisas desenvolvidas sobre a avaliação dos teores de polifenóis e atividade antioxidante em chocolates, com diferentes concentrações de liquor de cacau, relacionando os documentos de patentes depositados sobre esta tecnologia a respeito de quais países são os principais depositantes, a evolução anual dos depósitos e as principais áreas de aplicação. A utilização de estudos prospectivos tem sido bastante utilizada para auxiliar na tomada de decisões por empresas e universidades. Ressalta-se ainda que esta é uma atividade relativamente recente e decorre de um contexto de profundas mudanças principalmente no que tange a globalização da economia e a aceleração das mudanças tecnológicas, fruto do processo de inovação.

\section{DESCRIÇÃO DA TECNOLOGIA}

Segundo a legislação brasileira, o chocolate é definido como o produto preparado com cacau obtido por processo tecnológico adequado e açúcar, podendo conter outras substâncias alimentícias aprovadas (BRASIL, 1978).

Nos últimos anos, pesquisadores e produtores têm se tornado cada vez mais interessados em polifenóis (MANACH et al., 2004). As principais razões desse interesse são: a sua grande abundância na nossa dieta, o reconhecimento das propriedades antioxidantes dos polifenóis, e sua provável papel na prevenção de várias doenças associadas com o estresse oxidativo, tais como o câncer e doenças cardiovasculares e neurodegenerativas (MANACH et al., 2004). Além disso, os polifenóis, que constituem as substâncias ativas encontradas em muitas plantas medicinais, modulam a atividade de uma vasta gama de enzimas e receptores celulares (MIDDLETON et al., 2000). Desta forma, além de ter propriedades antioxidantes, os polifenóis têm várias outras ações biológicas específicas (MANACH et al., 2008).

Os polifenóis ou compostos fenólicos são uma classe de compostos que ocorrem em frutas, vegetais, nuts, sementes, flores, bebidas, ente outros. Constituem um dos mais numerosos e largamente distribuídos grupos de substâncias do reino das plantas, com mais de 8000 estruturas fenólicas conhecidas (BRAVO, 1998).

Pesquisas recentes vêm demonstrando potenciais efeitos benéficos à saúde providos pelos polifenóis encontrados nas sementes de cacau e conseqüentemente o chocolate. Estes compostos atuam em nosso organismo como antioxidantes, podendo prevenir a oxidação do colesterol de baixa densidade (LDL), um dos principais fatores etiológicos que levam às doenças coronárias. Também atuam na prevenção de cânceres, que estão diretamente relacionados com a carcinogênese genotóxica devida ao DNA reativo e aos agentes mutagênicos e não genotóxicos que atuam através de mecanismos promovidos epigenéticamente (WEISBURGER et al, 2000).

A oxidação lipídica é uma das principais reações deteriorativas a ocorrerem durante o processamento, distribuição, armazenamento e preparo final dos alimentos. É responsável pelo desenvolvimento de sabores e odores desagradáveis nos alimentos, tornando-os impróprios para o consumo. Além disso, ela também provoca outras alterações que irão afetar a qualidade nutricional, 
a integridade e a segurança dos alimentos, através da formação de compostos potencialmente tóxicos (FRANKEL, 1980; NAWAR, 1985; ARUOMA, 1993; KUBOW, 1993).

A oxidação nos sistemas biológicos ocorre devido à ação dos radicais livres no organismo. Estas moléculas são extremamente reativas e podem ser geradas por fontes endógenas ou exógenas. (MACHLIN et al, 1987).

Os processos oxidativos podem ser evitados através da modificação das condições ambientais ou pela utilização de substâncias antioxidantes com a propriedade de impedir ou diminuir o desencadeamento das reações oxidativas (ALLEN et al., 1983).

Antioxidantes fenólicos funcionam como seqüestradores de radicais e algumas vezes como quelantes de metais e também são eficazes para prevenir a oxidação lipídica (SHAHIDI et al., 1992),

Pesquisas têm-se dirigido no sentido de encontrar produtos naturais com atividade antioxidante os quais permitirão atuar como alimentos funcionais. Os estudos estão centralizados nos compostos fenólicos de origem vegetal, pois eles agem como aceptores de radicais livres, interrompendo a reação em cadeia provocada por estes, além de atuarem também nos processos oxidativos catalizados por metais, tanto in vitro, como in vivo (HO, 1992; HUANG et al., 1994; PRATT, 1992; HO et al., 1994; DONNELLY et al., 1995; CINTRA et al., 1996; WILLIAMSON et al., 1998).

\section{ESCOPO}

Para a pesquisa da tecnologia protegida ou descrita em documentos de patentes referente à avaliação dos teores de polifenóis e atividade antioxidante em chocolates, com diferentes concentrações de liquor, foi elaborada uma estratégia de busca que combinou os campos da Classificação Internacional de Patentes (IPC), nas quais os documentos relativos a esta tecnologia está classificada, associada a um conjunto de palavras-chave que representam as formas com as quais esta tecnologia poderia ser identificada nos documentos.

A partir deste método, foi realizada a pesquisa nas bases de dados on line do escritório europeu (Espacenet), visto que abrange patentes depositadas e publicadas em mais de 90 países, incluindo, por exemplo, os pedidos de patentes depositadas no Brasil (Instituto Nacional de Propriedade Industrial - INPI), norte americanos (United States Patent and Trademark Office - USPTO) e via Patent Cooperation Treaty (PCT). Independente da base europeia conter os documentos de patentes depositados no Brasil e Estados Unidos, foi realizada também a busca na base do INPI e USPTO para aumentar o escopo da pesquisa e tentar identificar os documentos que ainda não foram indexados na base européia (Espacenet).

Para a pesquisa nos bancos de dados foram utilizados termos ou palavras-chave em relação ao uso (chocolate*), aos compostos ativos (composto fenólico*, polifenol*, flavonóide*) e em relação às propriedades (antioxidante*), assim como as palavras-chave em inglês, chocolate*, phenolic compound*, polyphenol*, flavonoid*, antioxidant*. Também foram feitas buscas de publicações científicas nas bases de produção científica BVS, BIREME, CAPES, SciELO, WEB OF SCIENCE, GOOGLE ACADÊMICO, CSA e SCOPUS. 
A prospecção tecnológica foi realizada por meio de coleta, tratamento e análise das informações extraídas dos documentos de patentes encontrados. Vale destacar que o termo documento de patente abrange pedidos de patente publicados, arquivados ou patentes concedidas.

\section{RESULTADOS E DISCUSSÃO}

O resultado dessa pesquisa resultou em um universo de dados composto por 133 registros de documentos de patente referente à tecnologia de interesse. Entretanto, é importante ressaltar que o número encontrado não representa o total de invenções protegidas nesta área, isso porque uma mesma patente pode ser depositada em diferentes países, com o objetivo de garantir o direito de exclusividade aos seus inventores nos mercados considerados como mais relevantes, uma vez que o direito da patente é territorial (MACHADO et al., 2012).

A primeira patente identificada a respeito da tecnologia de interesse foi de 1998, tendo os Estados Unidos como país de origem. De acordo com a Figura 1, é possível observar uma linearidade do número de patentes entre 1998 e 2008. Contudo é importante reforçar que, durante 10 anos, apenas 83 patentes foram depositadas sobre a tecnologia de interesse.

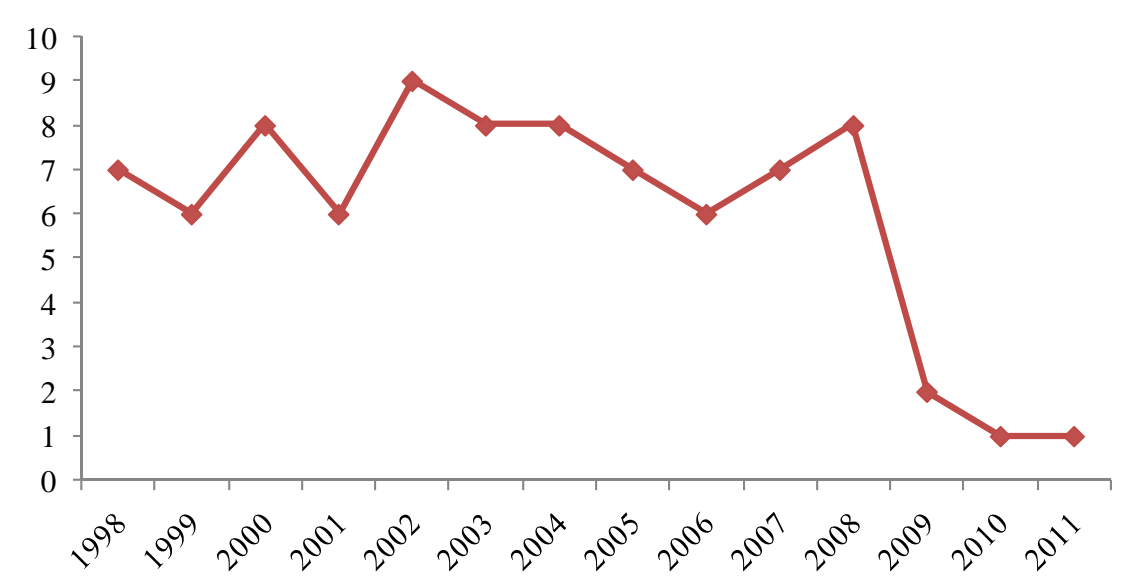

Figura1: Evolução anual do depósito de patentes de sobre avaliação dos teores de polifenóis e atividade antioxidante em chocolates, com diferentes concentrações de liquor na Base Europeia de patentes. Fonte: Autoria própria, 2012.

No período investigado, em 2010 e 2011 foram depositadas apenas uma patente por ano, sendo o menor número observado no período. Vale salientar que muitos documentos depositados em 2010, 2011 e 2012 podem não estar disponíveis devido ao período de sigilo que é de 18 meses após a data do depósito, sendo portanto, este o período limitante da busca.

A partir da análise dos resultados relativos ao depósito dos documentos de patentes, no que diz respeito aos países nos quais se originou a tecnologia patenteada, sendo esta pesquisa feita através da identificação do país de origem do depositante, é possível observar que esta tecnologia se 
encontra bastante centralizada nos países mais desenvolvidos. A Figura 2 demonstra que os Estados Unidos se destaca por ser o maior detentor das patentes referentes a chocolates com alto teor de polifenóis e com propriedades antioxidantes. Essas patentes depositadas podem, então, ser classificadas quanto ao processo e quanto ao seu campo de aplicação (Figura 3).

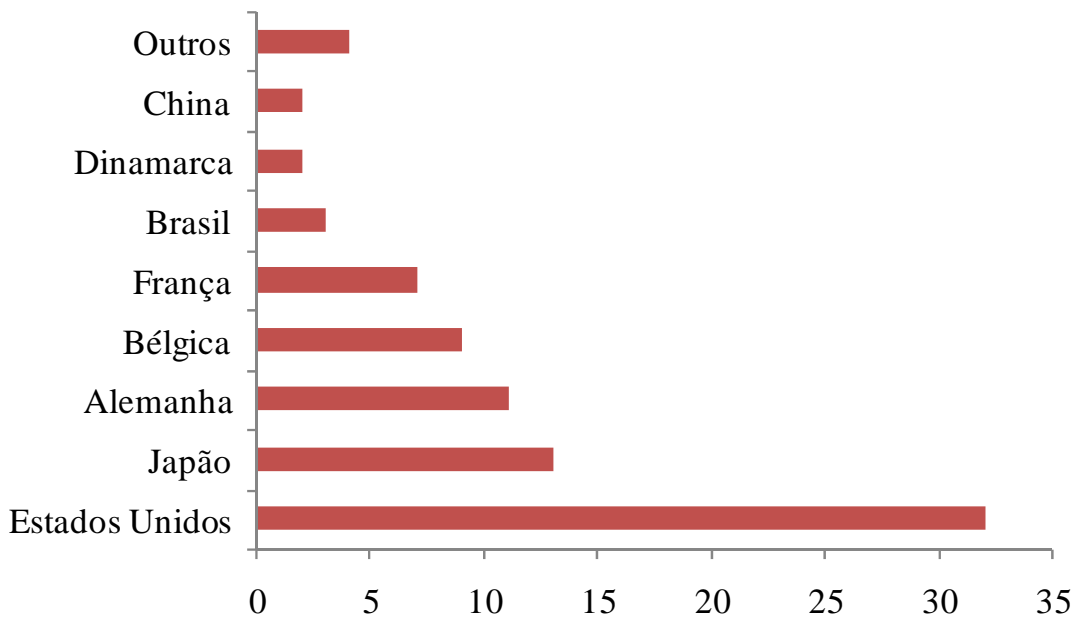

Figura 2: Distribuição de depósitos por país de origem da tecnologia pesquisada. Fonte: Autoria própria, 2012.

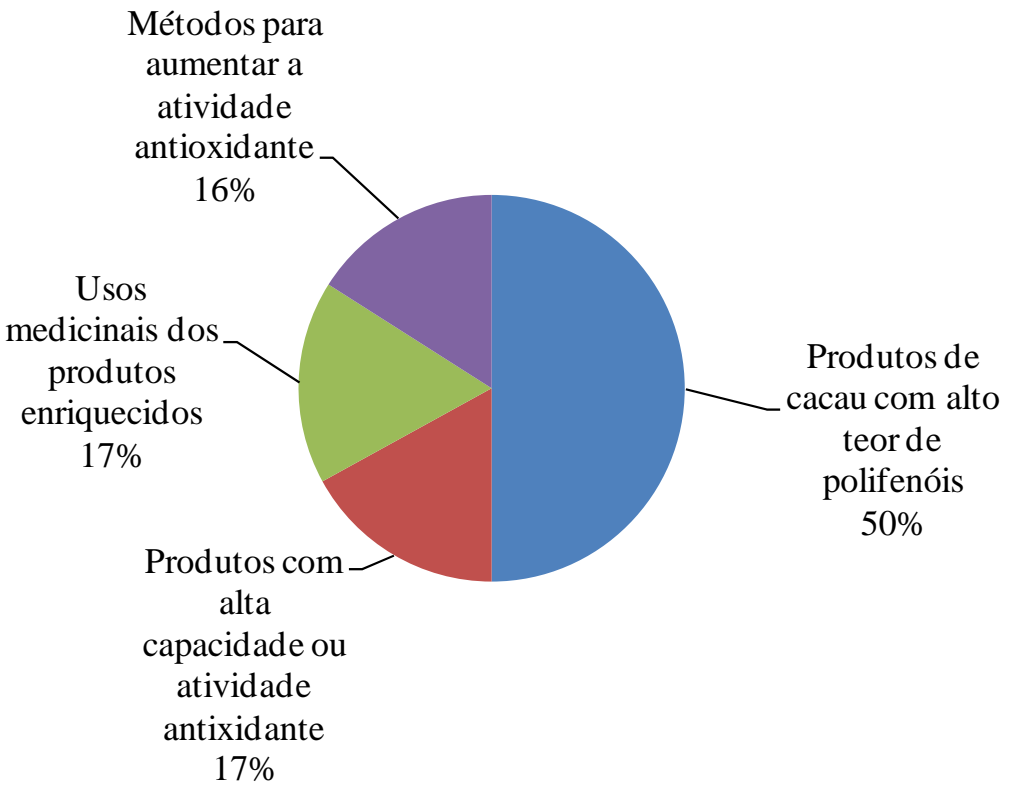

Figura 3: Distribuição percentual de patentes por Áreas de aplicação. Fonte: Autoria própria, 2012. 
A maioria das patentes, cerca de $50 \%$, está relacionada aos métodos de obtenção de derivados (chocolate) de cacau com alto teor de polifenóis. Por exemplo, o processo de obtenção de amêndoas, massa de cacau (liquor), cacau em pó e chocolates com elevada retenção dos compostos fenólicos, principalmente da classe dos flavonóides - Priscila Efraim - Brasil - 2004.

Outros 16\% das patentes referem-se a métodos para aumentar a atividade antioxidante do chocolate.

Além disso, é possível observar que as pesquisas em relação ao chocolate estão sendo realizadas nas seguintes áreas (Figura 3): desenvolvimento de produtos (chocolate) com alta capacidade ou atividade antioxidante (17\%), e utilização medicinal, como o benefício do chocolate no tratamento de doenças cardiovasculares (17\%).

A Figura 4 mostra que as pesquisas realizadas em relação ao chocolate, nos 31 periódicos, representam, em cerca de $40 \%$, pesquisas quanto à utilização medicinal - como o chocolate pode beneficiar no tratamento de doenças cardiovasculares. Além disso, 26\% das pesquisas referem-se aos benefícios à saúde que os polifenóis contidos nos derivados de cacau podem proporcionar. Outros $13 \%$ estão relacionadas à determinação de polifenóis em derivados de cacau, enquanto outros $13 \%$ das pesquisas referem-se ao desenvolvimento de produtos (chocolate) com alta capacidade ou atividade antioxidante. Por fim, cerca de 6\% das patentes obtidas na pesquisa relaciona-se a avaliações da ação dos antioxidantes dos derivados de cacau e, outros 3\%, dizem respeito aos processos e/ou métodos de obtenção de derivados (chocolate) de cacau com alto teor de polifenóis.

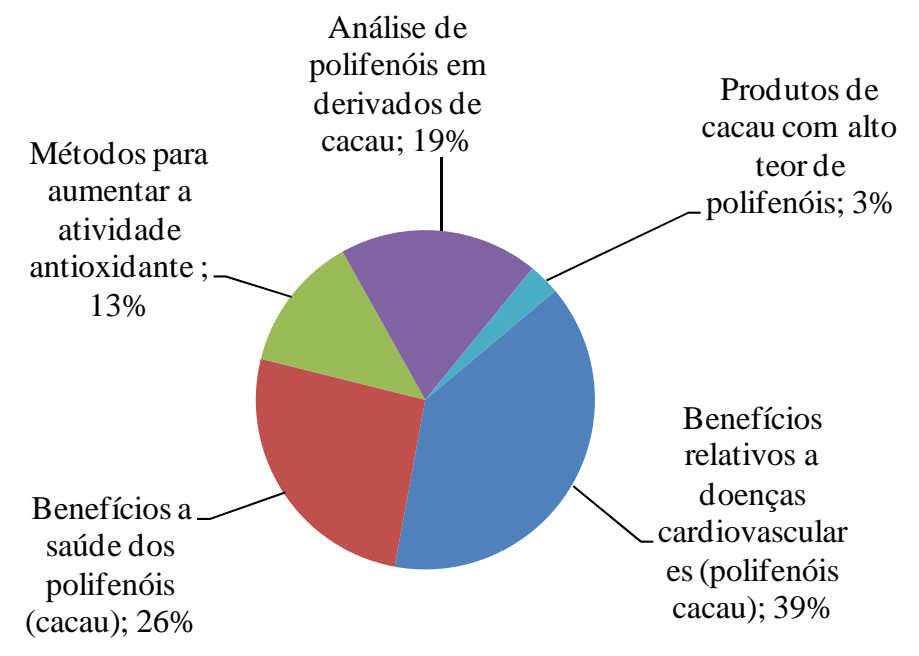

Figura 4: Áreas de aplicação referentes às publicações encontradas na pesquisa em bases de dados de produção científica. Fonte: Autoria própria, 2012. 


\section{CONCLUSÃO}

A prospecção tecnológica mostrou que há poucas patentes relacionadas ao uso do chocolate como uma fonte de fenólicos antioxidantes para a população. Além disso, ainda é necessário comprovação de que os polifenóis exercem esses efeitos in vivo. Um pré-requisito para essa comprovação é avaliar se os polifenóis são absorvidos através da dieta, sendo que cada vez mais são demonstradas provas dessa absorção. Porém, é necessário esclarecer qual a concentração efetiva e quais concentrações possibilitam os efeitos esperados através do consumo alimentar.

Outra questão aberta está relacionada com o metabolismo do polifenol. Por exemplo, muito esforço foi investido para mostrar os efeitos antioxidantes de polifenóis livres especialmente catequinas e flavonol quercetina. No entanto, apenas uma pequena parte pode ser encontrada no plasma na forma livre, mas conjugados ou mesmo metabolizados a vários ácidos fenólico.

Alguns dados são promissores e justificam uma posterior investigação mais aprofundada em campo, sendo necessárias pesquisas futuras de modo a confirmar se a ingestão dos compostos funcionais e/ou as suas fontes estão relacionadas com mensuráveis efeitos na saúde humana e/ou no desenvolvimento de doenças. Assim, as pesquisas em artigos, teses e dissertações possibilitaram a confirmação dos resultados identificados nas patentes.

\section{REFERÊNCIAS}

ALLEN, J. C., HAMILTON, R.J. Rancidity in foods. London: Applied Science, 1983. 199p.

ARUOMA, O. I. Free radicals and food. Chemistry in Britain, v.29, n. 3, p. 210-214, 1993.

BRASIL, Ministério da Saúde. Agência Nacional de Vigilância Sanitária. Resolução RDC no 12, de 24 de jul. 1978, Normas técnicas especiais, revistas pela CNNPA, relativas a alimentos (e bebidas). Disponível em: <http://www.anvisa.gov.br/legis/resol/12_78_bombons.htm>. Acessado em: 12 abr. 2009.

BRAVO, L. Polyphenols: chemistry, dietary sources, metabolism, and nutritional significance. Nutrition Reviews, v.56, n. 11, p. 317-333, 1998.

CINTRA, R. M. G., MANCINI FILHO, J. Antioxidant activity of spices in different systems. In: BIENNIAL MEETING INTERNATIONAL SOCIETY FOR FREE RADICAL RESEARCH, 8, 1996, Barcelona. Anais... Barcelona v. 8, p. 90, 1996.

COSGROVE, J. P.; CHURCH, D. F.; PRYOR, W. A. The kinetics of autoxidation of polyunsaturated fatty acids. Lipids, Champaign, v.22, n. 5, p. 299-304, 1987.

DONNELLY, J. K., ROBINSON, D. S. Invited review. Free radical in foods. Free Radical Research, v.22, n. 2, p. 147-176, 1995.

EFRAIM, P. Estudo para minimizar as perdas de flavonóides durante a fermentação de sementes de cacau para produção de chocolate. 2004. 126f. Dissertação (Mestrado em Tecnologia de Alimentos) Universidade Estadual de Campinas. Faculdade de Engenharia de Alimentos. Campinas, SP, 2004.

EFRAIM, P. Contribuição à melhoria de qualidade de produtos de cacau no Brasil, através da caracterização de derivados de cultivares resistentes à vassoura-de-bruxa e de sementes 
danificadas pelo fungo. 2009. 208f. Tese (Doutor em Tecnologia de Alimentos) - Faculdade de Engenharia de Alimentos, Universidade Estadual de Campinas, Campinas, SP, 2009.

FRANKEL, E. N. Lipid oxidation. Progress in Lipid Research, v.19, n. 1-2, p. 1-22, 1980.

HUANG, T. M., ROSEN, R. T. Food phytochemicals for cancer prevention. American Chemical Society, p.2-19, 1994.

HSIEH, R.J., KINSELLA, J.E. Oxidation of polyunsaturated fatty acids: mechanisms, products, and inhibition with emphasis on fish. Advances in Food and Nutrition Research, v.33, p.233-341, 1989.

HUANG, M.T., FERRARO,T. Cancer chemoprevention by phytochemicals in fruits and vegetables: an overview. In: HO, C.T., OSAWA, T., HUANG, T.M., ROSEN, R.T. Food phytochemicals for cancer prevention. American Chemical Society, n. 546, p. 2-16, 1994.

ICCO. International Cocoa Organization. Produção mundial de cacau. Disponível em: http://www.icco.org/. Acessado em: 16 out. 2011.

KUBOW, S. Lipid oxidation products in food and atherogenesis. Nutrition Reviews, v.51, n. 2, p. 33-40, 1993.

LOPES, U. V.; MONTEIRO, W. R.; PIRES, J. L.; ClEMENT, D.; YAMADA, M. M.; GRAMACHO, K. P. Cacao breeding in Bahia, Brazil - strategies and results. Crop Breeding and Applied Biotechnology, v.1, p. 73-81, 2011.

MACHADO, B. A. S.; REIS, J. H. O.; FIGUEIREDO, T. V. B.; DRUZIAN, J. I. Mapeamento tecnológico da goma xantana sob o enfoque em pedidos de patentes depositados no mundo entre 1970 a 2009. Revista Geintec. v.2, n. 2, p. 154-165, 2012.

MACHLIN, L.J.; BENDICH, A. Free radical tissue damage: protective role of antioxidant nutrients. FASEB Journal, v.1, n.6, p.441-445, 1987.

MANACH, C.; SCALBERT, A.; MORAND, C.; RÉMÉSY, C; JIMÉNEZ, L. Polyphenols: food sources and bioavailability. Am J Clin Nutr., v. 79, n. 5, p. 727-47, 2004.

MARTINI, M. H. Caracterização das sementes de seis espécies de Theobroma em relação ao Theobroma cacao L. 2004. 98f. Tese (Doutor em Alimentos e Nutrição) - Faculdade de Engenharia de Alimentos, Universidade Estadual de Campinas, Campinas, SP, 2004.

MIDDLETON. E.; KANDASWAMI, C.; THEOHARIDES, T. C. The effects of plant flavonoids on mammalian cells: implications for inflammation, heart disease, and cancer. Pharmacol Rev, v.52, p. 673-751, 2000.

NAWAR, W. W. Lipids. In: FENNEMA, O.R. (Ed.). Food Chemistry. $2^{\mathrm{a}}$ ed. Marcel Dekker, p. 139-244, 1985.

OTTERER, M. Aula: tecnologias de obtenção do cacau e do chocolate. Universidade de São Paulo. Escola superior de agricultura "Luiz de Queiroz". Departamento de agroindústria, alimentos e nutrição. Piracicaba, SP, 1999.

PRATT, D. E.; BIRAC, P. M. Source of antioxidant activity of soybean and soy products. Journal of Food Science, v.44, p. 1720-1722, 1979. 
SHAHIDI, F.; JANITHA, P.K., WANASUNDARA, P.D. Phenolic antioxidants. Critical Reviews in Food Science and Nutrition, v.32, n. 1, p. 67-103, 1992.

WEISBURGER, J. H.; WILLIAMS, G. M. The distinction between genotoxic and epigenetic carcinogens and implication for cancer risk. Toxicology Science, v.49, p. 231-246, 2000.

WILLIAMSON, G.; FAULKNER, K.; PLUMB, G.W. Glucosinolates and phenolics as antioxidants from plant foods. European Journal of Cancer Prevention, v.7, n.1, p.17-21, 1998.

WOLLGAST, J.; ANKLAN, E. Review in polyphenols in theobroma cacao: changes in composition during the manufacture of chocolate and methodology for identification and quantification. Food Research International, n. 33, p. 423-447, 2000. 